\title{
Treatment Plans of Settlement Deformation at Expressway Tunnel Portal Area
}

\author{
Enkuan Tang ${ }^{2, a}$, Likui Huang ${ }^{1, b}$, Daiguang Chen ${ }^{2, c}$, \\ Qing Shen ${ }^{1, d}$, Wenbin $\mathrm{Wu}^{1, \mathrm{e}}$ \\ ${ }^{1}$ College of Civil Engineering, Hunan University, China \\ ${ }^{2}$ China Construction Fifth Engineering Bureau Co. LTD \\ atangenkuan@cscec.dz, ${ }^{b}$ huanglikui@hnu.edu.cn, ${ }^{c}$ chendaiguang@cscec.dz, \\ dshenging@hnu.edu.cn, ${ }^{\mathrm{e}}$ wuwenbin@hnu.edu.cn
}

Keywords: tunnel portal area; settlement deformation; treatment plan; monitoring

\begin{abstract}
This paper presents the cause analysis, treatment plans and treatment results of a settlement deformation accident at tunnel portal area of left line T1 tunnel in Algeria North-South Expressway. The engineering practice demonstrated the feasibility, timeliness, and safety of the treatment plans. The successful handling of the accident provided an important reference for the formulation of the settlement deformation treatment plans in the tunnel portal areas.
\end{abstract}

\section{Introduction}

According to construction experience, the geological conditions of the mountain tunnels are mostly complex, and the surrounding rock of tunnel portal areas is generally more fragmented and loose. Since the front slope will destroy the original balance state of the mountain, the geological conditions of tunnel portal areas are often extremely complex. However, the tunnel portal area is the starting and key links of tunnel construction. The mountain disequilibrium caused by construction is the key inducement factor of settlement deformations at shallow cover area of tunnel portal. Once settlement deformations at tunnel portal area occur, it is significant to take an effective construction plans to ensure the safety of construction operation process.

\section{Overviews of engineering background}

T1 tunnel in Algeria North-South Expressway is located in $6 \mathrm{~km}$ south away from Chiffa town, Blida province. The left line and right line of the tunnels are designed separately, and the beginning and ending mileages are PK5+758 PK8+145 and LK5+757 LK8+128, respectively. The lengths of left line and right line are $2371 \mathrm{~m}$ and $2387 \mathrm{~m}$, respectively. The design height of the tunnels is $7.57 \mathrm{~m}$, and the design width is $13.5 \mathrm{~m}$ with bi-directional 6 lanes. The design speed of tunnels is 80 $\mathrm{km} / \mathrm{h}$. The maximum cover depth of the tunnels is $345 \mathrm{~m}$ with a complex geological condition. The surrounding rock of tunnel portal areas is mainly composed of strongly weathered soft and fractured black carbonaceous shale, which is partly clamped by mud and accompanied by seepage.

\section{Analysis of causes of settlement deformation at portal areas of T1 left tunnel}

From December 2014, it began a continuous five months rainy season in Algeria. The slope soil was soft and rainwater infiltrated along the surface fissure, which made the slope soil highly saturated. The mechanical properties of the rock and soil became worse, thus it resulted in the instability and cracking of slope rock (figure 1). Also, there was a surge of water spring in the LK5+780 mileage of the left tunnel, and excavation of the tunnel was always accompanied by the water flow (figure 2). Because of the long-term erosion of the groundwater, the bottom rock about $12 \mathrm{~m}$ surrounding the tunnel portal was muddy, and the bearing capacity was weakened significantly (figure 3). The high degree of saturation of internal water content of rock also caused the stabilizing ability of surrounding rock to be greatly reduced. Therefore, the excavation of the lower step would eventually lead to the cracking of the front slope and the settlement deformation of the supporting part in the tunnel (figure 4).

\section{Treatment plans of settlement deformation at portal areas of $\mathrm{T} 1$ left tunnel}

In January 22, 2015, when the portal of T1 left tunnel was excavated from the middle steps to the LK5+780, there appeared a number of cracks in the initial support face and there was a trend of continuous development. The workers immediately stopped the excavation operation and informed 
the managers to check, and then managers found drums and cracks in the concrete face of the front slope and circumferential cracks in the initial support face of tunnel portal. The various indications shown that the supporting structure of the portal had been destabilized, and the deformation had occurred, which meant there might be danger of collapse at any time. In order to ensure personal safety, all construction operations in the tunnel were suspended, and all personnel were evacuated. It was urgent to take measures to reinforce the settlement deformed areas and prevent the settlement from continuous development.

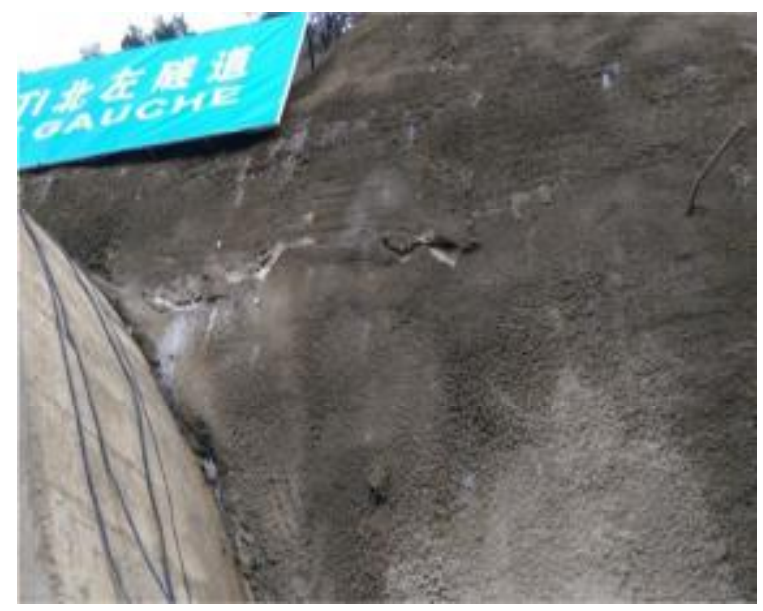

Fig.1 Cracking of front slope at tunnel portal

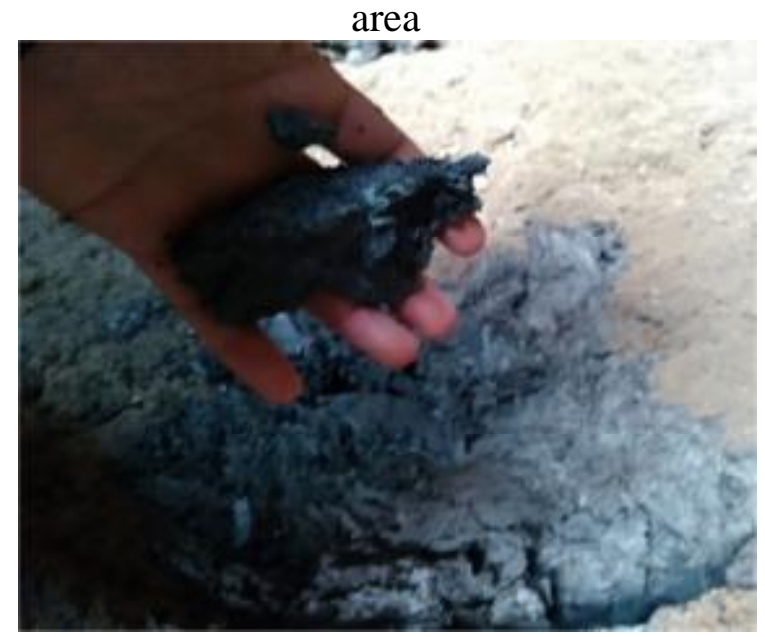

Fig.3 Rock mud in the bottom of the tunnel

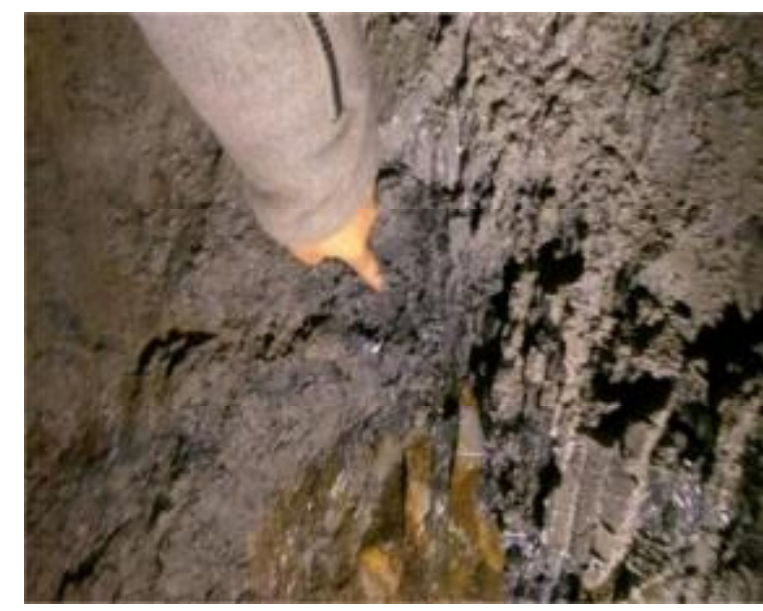

Fig.2 A surge of water spring in the LK5+780 mileage

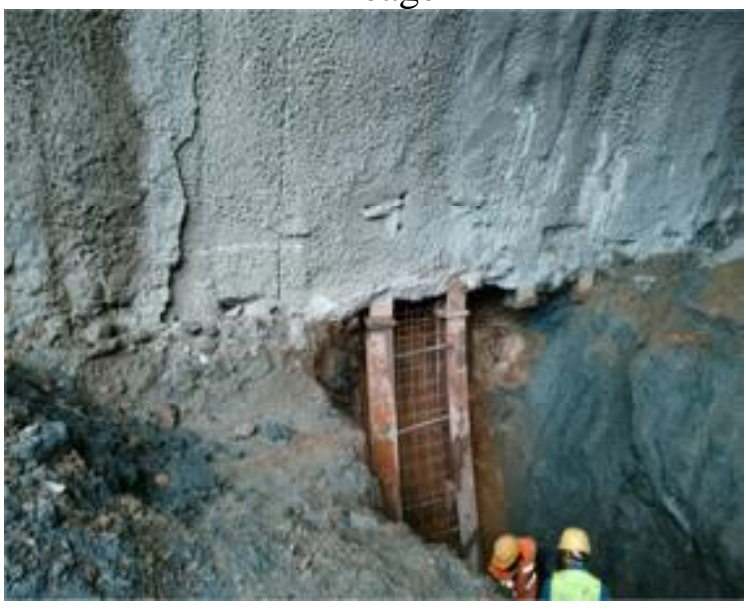

Fig.4 Cracking of initial supporting face inside the tunnel

The emergency plans were launched immediately after on-site meeting of design department and the project department. The following measures were taken for the settlement deformation.

1) All excavation was stopped immediately. The rock face was closed with the shotcrete technology. The area of LK5+780 that had been excavated was backfilled.

2) The back pressure filling of the arch foot was carried out immediately to ensure the stability of the slope and the arch, and prevent the entire broken face from sliding forward (figure 5).

3) The longitudinal beams were set in the tunnel. Longitudinal joists were installed at the arch foot of upper steps and $60 \mathrm{~cm}$ above arch foot of middle steps. The HEB180 steel was $24 \mathrm{~m}$ in length as the bracket material, and it was required to be firmly welded with each arch to ensure the overall stability of the initial support structure (figure 6).

4) Micro piles were added to the arch foot of the lower steps (figure 7). The micro piles were placed on both sides of the lower steps and welded with the arch. The micro piles adopted seamless steel tube with $\phi=101.5 / 88.9 \mathrm{~mm}$, a wall thickness of $6.3 \mathrm{~mm}$ and a length of $6 \mathrm{~m}$. Grouting is adopted with $\mathrm{C} / \mathrm{E}=0.5$ for micro piles and grouting pressure was $0.8 \sim 1.5 \mathrm{MPa}$. The micro piles were added in LK5+770 LK5+790 range. 
5) The middle steps were set up as a temporary inverted arch. In the LK5+770 LK5+790 section, the temporary invert arch (HEB180 steel) was adopted to ensure that the middle steps were closed to form whole forcing state (figure 8).

6) The diagonal braces were used as temporary supporting structures to prevent the settlement of the arch. The diagonal braces were welded by two HEB220 steels with a length of $12 \mathrm{~m}$ (figure 9).

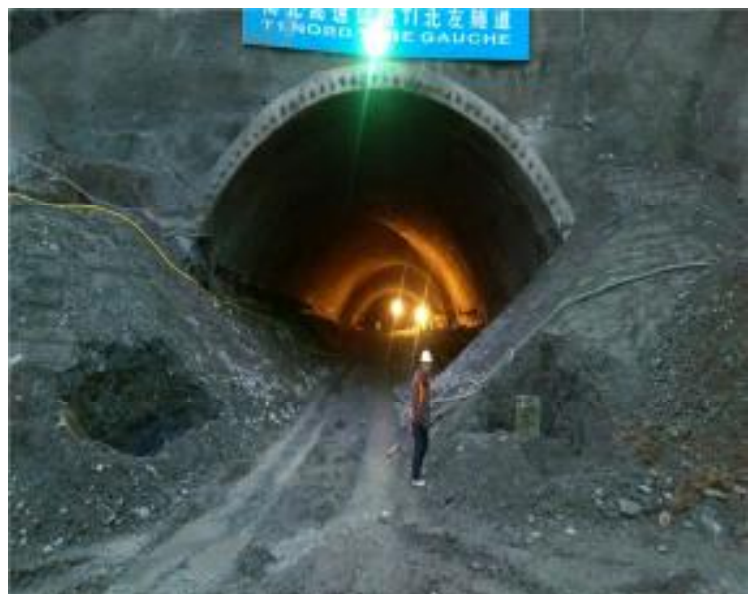

Fig.5 Back pressure filling of the arch at tunnel portal area

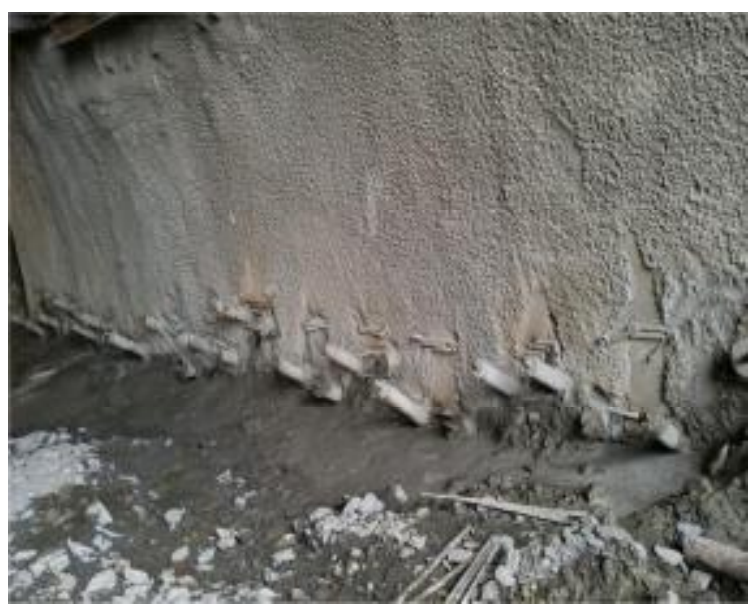

Fig.7 Setting up micro piles and grouting

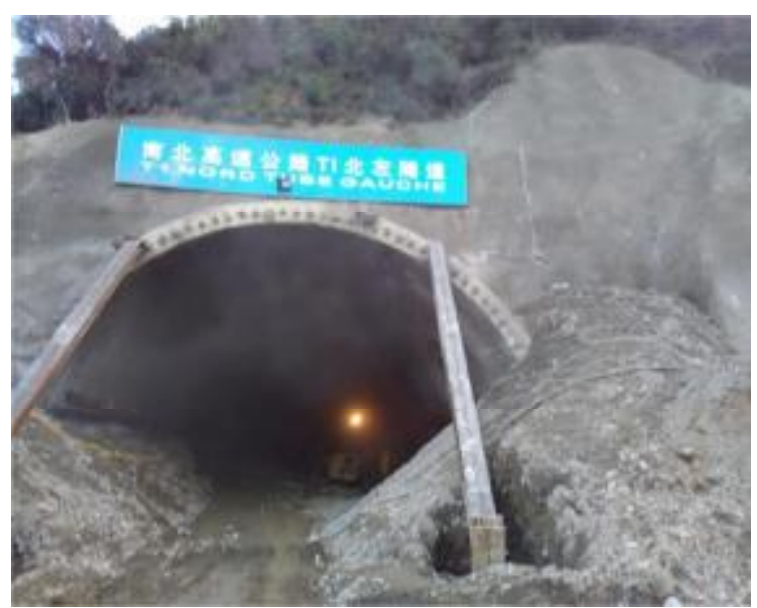

Fig.9 Setting up temporary inverted arch for middle steps

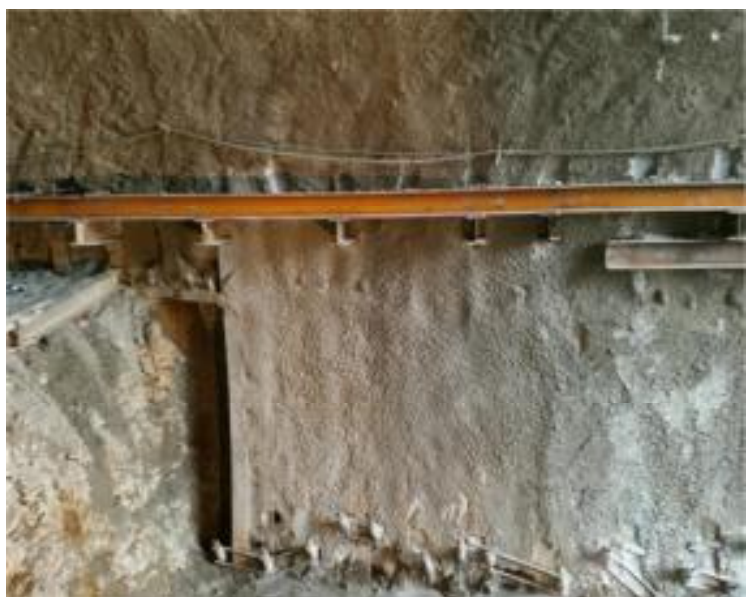

Fig.6 Setting up longitudinal beams

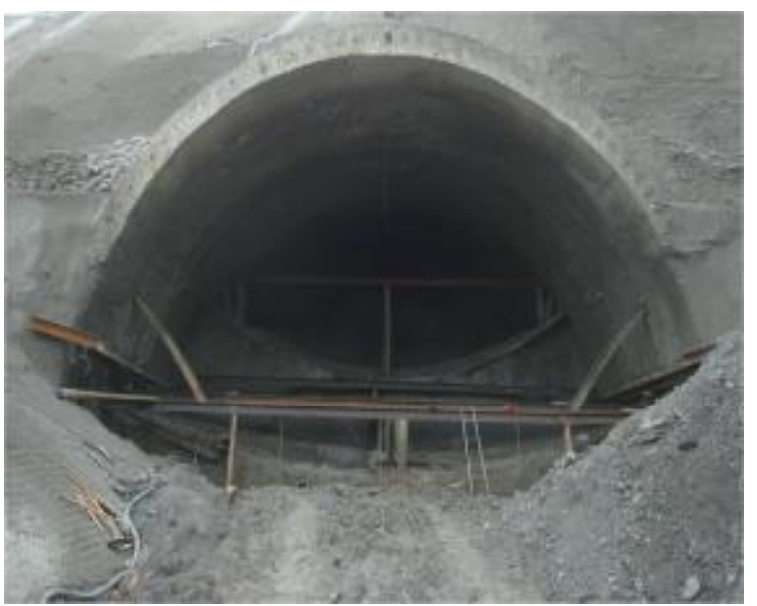

Fig.8 Setting up temporary inverted arch for middle steps

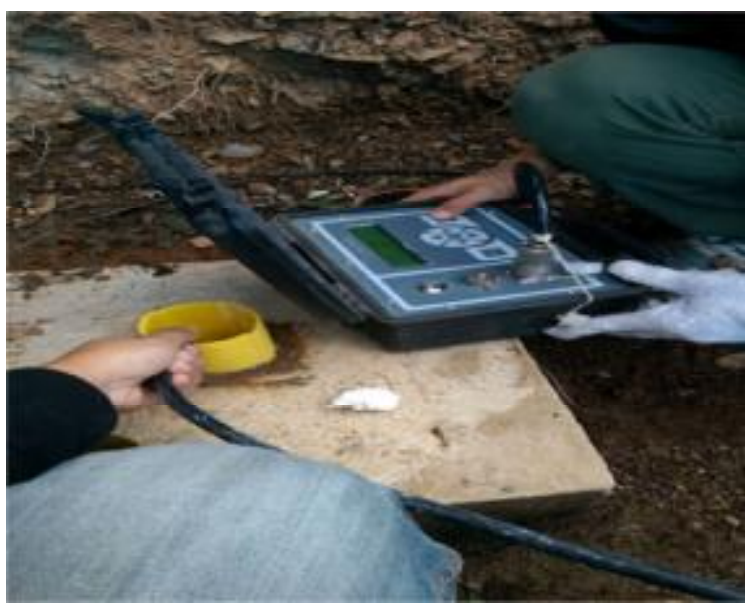

Fig.10 Deep-hole observation instruments 
7) A real-time monitoring of the settlement deformation was adopted. In the deformed area of the tunnel, a reflector was buried for the observing of total station. The observation frequency was twice a day and the data was compared and analyzed in time. The deep-hole observation pile in the tunnel roof was monitored by deep-hole observation instruments every day and the data was recorded in time (figure 10).

8) The safety awareness of the construction staff was enhanced, and the construction plans were organized reasonably. During the construction of the left tunnel, a special person was arranged for observation. Once any danger occurred, the construction personnel would be notified in time to evacuate. After the temporary inverted arch was closed in the left tunnel, the inverted arch was not excavated. When the observation data showed that the settlement deformation had stopped, the inverted arch could be excavated, and the construction of the secondary lining was prepared after the rainy season.

\section{Monitoring and analysis of settlement deformations}

The surface and deep-hole observation piles were set to monitor the settlement deformations in the tunnel portal section (figure 11). The observation points were arranged in appropriate locations inside the tunnel to monitor the deformations in different directions. The deformation data was regularly recorded at a certain frequency.

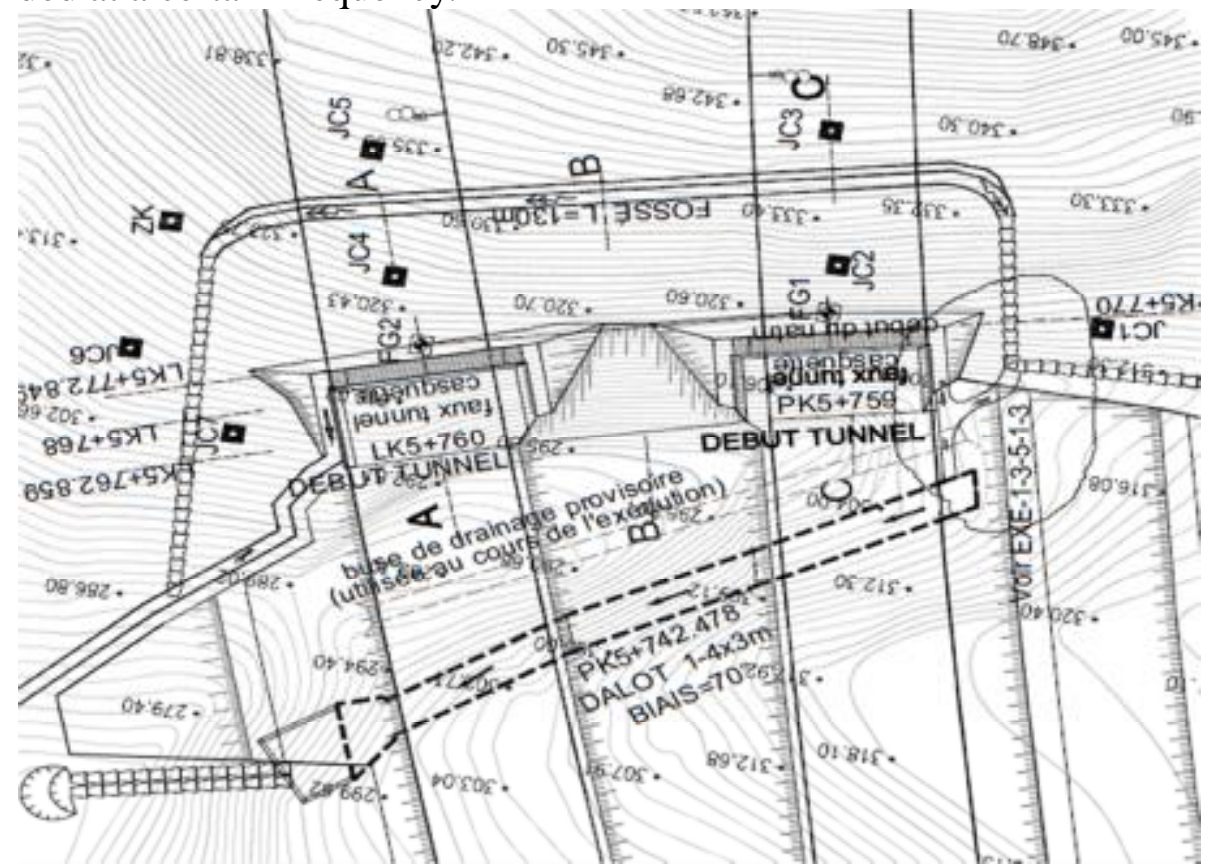

Fig.11 Detailed layout of surface and deep-hole observation piles outside the tunnel

Through the analysis of the deformation data, the surface deformations outside the tunnel portal were mainly vertical settlements with the maximum vertical displacement of $131 \mathrm{~mm}$ and the maximum horizontal slip (toward the outside direction) of $62 \mathrm{~mm}$. The deformations inside the tunnel were mainly vertical settlement with the maximum vertical displacement of $180 \mathrm{~mm}$ and the maximum horizontal convergence of $51 \mathrm{~mm}$.

From the observation data, the maximum deformation occurred in January 22, 2015, and the maximum deformation rate occurred in January 22 to January 25, 2015. After January 25, the deformation curves of observed points inside and outside the tunnel tended to be stable, and the data changes returned to normal. In this case, it could be concluded that the measures taken for the settlement deformation of the portal of T1 left tunnel during January 22 to January 25 period were economical and effective, which had successfully prevented the further development of the settlement deformation.

\section{Conclusions}

Due to the special geological conditions, the tunnel construction in portal areas has always been difficult and key points. Once the settlement deformation of the tunnel portal occurs, how to quickly 
and safely take measures to ensure construction safety and progress of construction is particularly important. Through the brief analysis of the measures taken to deal with the settlement deformation of the tunnel portal in Algeria North-South Expressway, this paper demonstrated the timeliness, validity, safety and rationality of the measures taken in the tunnel. The construction measures involved in this paper were only parts of treatments in solving settlement deformation problems, which is still of great reference to the settlement deformation problems at the tunnel portal areas.

\section{References}

[1] J. Huang, Z. Liu: Settlement Analysis and Deformation Prediction of Tunnel Portal. Modern Tunnel Technology, 2007, (04): 32-35.

[2] D. Wei, H. Yang: Analysis of Ground Settlement and Deformation Control of Tunnel with Shallow Buried Bias Section. Western Traffic Science and Technology, 2012, (09): 47-49.

[3] J. Wei, Z. Zhang, H. Zhang: Monitoring Analysis and Prediction of Settlement and Deformation of Expressway Tunnel Portal Section. Traffic and Transportation Standardization, 2010, (07): 57-60. 